\title{
The fatigue stress on laser welded joints of DC06EK steel
}

\author{
Mária Mihaliková1 ${ }^{*}$, Anna Špegarová ${ }^{1}$, Jozef Petrik ${ }^{1}$ and Matej Babič² \\ ${ }^{1}$ FMMR TUKE, UMIK, Letná 9, 04402 Košice, Slovensko \\ ${ }^{2}$ Jožef Stefan Institute, Ljubljana, Slovenia
}

\begin{abstract}
The paper analyses the influence of the fatigue characteristics of laser welding steels sheets. The combination of laser welded steel sheets DC06EK has been subjected to fatigue stress testing. To assess the condition of the material under the cyclic stress and to determine the material characteristics such as fatigue or resp. fatigue time limit was performed according to STN 420363 . Fatigue tests were performed on the test piece. The experimental material had a laser weld with a rough surface. The test specimens were subjected to a pulsating positive disappearing thrust at a constant value of the coefficient of unbalance of $0<\mathrm{R} \ll 1$ and a frequency of $25 \mathrm{~Hz}$. The fatigue limit was determined at $260 \mathrm{MPa}$. The analysis of fracture surfaces showed on the sides of the weld joint the formation of a de-cohesive fracture. The resulting test values graphically presents stress-number curve.
\end{abstract}

\section{Introduction}

Parts of machinery, equipment, products within the industry are often exposed to regularly recurring mechanical, thermal and thermal-mechanical stress, which is called cyclic. Repetitive load is significantly influenced by internal and external factors that lead to the formation of microscopic and macroscopic material damage [1-4]. At a short number of cycles of deformation process can be characterized as a return, because there is no permanent degradation of the material. The stress $\sigma$ induced by this load is less than the Rm of the material ( $\sigma$ not exceeding the static load values), so the damage accumulates until the component breaks $[4,5]$. The fatigue rupture occurs after exhausting deformation capability in micro and creating microcracks, to macrocracks that subsequently spread.

Currently, the industry is increasingly applied laser beam welding. The laser is a significant atypical and intense local heating source, which has now use in various industries, such as energy, transportation, electronics, armaments, but especially in engineering. Development of technology using laser and a better understanding of the fundamental aspects of the interaction beam - material opened new horizons not only in the field of laser bonding, but also cutting of materials by laser [3]. Steel DC06EK / interstitial free/ are alloyed with a small percentage of niobium, titanium, phosphorus, boron, or a

* Corresponding author: maria.mihaliková@tuke.sk 
combination thereof. These elements are able to bind nitrogen and carbon atoms to stable precipitates. The good formability of the sheet due to the low percentage of only carbon and alloy steels of these elements [2]. DC06EK steels are used for many industrial applications that require steel with good ductility and high strength [5].

\section{Experimental procedures}

Laser welded steel sheets of type DC06EK of $1.2 \mathrm{~mm}$ thickness were used for experimental material. The chemical composition of the investigated steel is shown in Table 1. Laser welding of experimental materials was carried out at the Slovak Technical University in Bratislava, Faculty of Materials Science and Technology in Trnava. Laser welding parameters are shown in Table 2

Table 1. Chemical composition of steel DC06EK [wt. \%].

\begin{tabular}{|c|c|c|c|c|c|c|c|c|c|c|}
\hline $\mathbf{C}$ & $\mathbf{S}$ & $\mathbf{N}$ & $\mathbf{M n}$ & $\mathbf{P}$ & $\mathbf{S i}$ & $\mathbf{A l}$ & $\mathbf{N i}$ & $\mathbf{N b}$ & $\mathbf{V}$ & $\mathbf{T i}$ \\
\hline 0.001 & 0.011 & 0.002 & 0.082 & 0.011 & 0.006 & 0.055 & 0.013 & 0.001 & 0.002 & 0.040 \\
\hline
\end{tabular}

One aspect of assessing the complexity of steel characteristics is the determination of carbon equivalent $\left(\mathrm{C}_{\mathrm{e}}\right)$. $\mathrm{C}_{\mathrm{e}}$ informative used to determine the weldability of steel. For steels with a carbon content of less than $0.22 \mathrm{wt}$ \%, it is calculated according to (1) [6]:

$$
C_{e}=C+M n / 6+C r / 5+N i / 15+M o / 4+C u / 13+P / 2+0.0024 t
$$

For steel DC06EK $C_{e}=0.035 \%$. Steel has good weldability.

Table 2. Welding parameters for laser welded DC06EK steels.

\begin{tabular}{|l|l|}
\hline \multicolumn{2}{|c|}{ Laser welding parameters } \\
\hline laser beam power & $2000 \mathrm{~W}$ \\
\hline laser beam speed & $40 \mathrm{~mm} \cdot \mathrm{s}^{-1}$ \\
\hline focal position & $1 \mathrm{~mm}$ above the material surface \\
\hline optical fiber diameter & $200 \mu \mathrm{m}$ \\
\hline protective gas & helium \\
\hline
\end{tabular}

To obtain the basic material characteristics was performed tensile testing at ambient temperature in accordance with EN ISO 5178: 2011 [7].

The structural analysis of the laser-welded plates was carried out using Olympus Vanox T-AH2 light microscope. Metallographic specimens for microstructure observation were prepared by standard metallographic methods, which included hot casting of plastics, grinding on abrasive paper at various granularities followed by polishing with diamond paste and OP-S Suspension emulsion. $2 \% \mathrm{Nital}\left(2 \mathrm{ml} \mathrm{HNO}_{3}, 98 \mathrm{ml}\right.$ ethyl alcohol) was used to induce microstructure of steels and laser welds. The grain size of the base materials was determined by the Jeffriess method according to STN 420462 [8].

The microhardness test was carried out in accordance with ISO / DIS 6507-1 [10]. The distance of the lines of stitches surface: $0.2 \mathrm{~mm}$. Measurements were made according to 
Vickers on a Struers Duramin 5 instrument with a Vickers indenter with a load of $980.6 \mathrm{mN}$ $(100 \mathrm{~g})$ and a holding time of $10 \mathrm{~s}$. HV0.1 Microhardness was measured on metallographic samples in a polished state at room temperature across the weld joint of lines, thereby detected values of micro hardness of the base material (BM), heat affected zone (HAZ) and weld metal (WM) [9].

To determine the fatigue strength values were conducted fatigue tests according to STN 420363 [11]. Used equipment servo-hydraulic Pulse INSTRON 8511 under the controlled force. Fatigue tests were performed on 18 flat test specimens. The test specimens are stressed in the affirmative disappearing pulsating tension at constant waveform asymmetry coefficient $0<\mathrm{R}<1$, and a frequency of $25 \mathrm{~Hz}$. The microstructures were observed by using Olympus Vanox-T microscopy. The JEOL JSM 7000F scanning electron microscope was used to observe fracture surface morphology.

\section{Results and discussion}

\subsection{Microstructure}

The microstructure of the base material (BM) of the steel DC06EK Fig. 1 is formed by a polyedric ferrite with an uneven grain size. The average grain size of ferrite is $\approx 25 \mu \mathrm{m}$. The welded joint (WJ) of the welded steels DC06EK is shown in Fig. 2. Welded joints reach width $\approx 1 \mathrm{~mm}$. In the heat-affected area (HAZ) at the transition to BM, a coarsegrained ferritic structure was formed Fig. 3. Ferritic grains are elongated in the direction of rapid heat dissipation into the weld metal [12]. The structure of the weld metal (WM) in Fig. 3 is composed of polyedric ferrite and bainite.

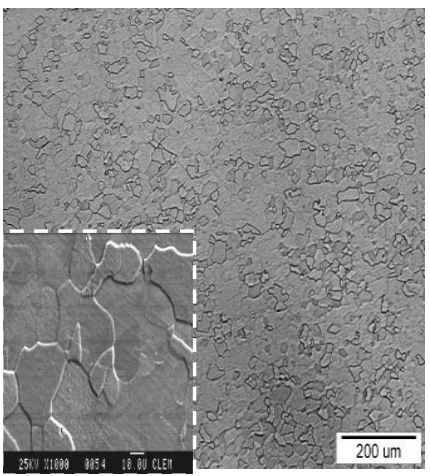

Fig. 1. Microstructure of BM.

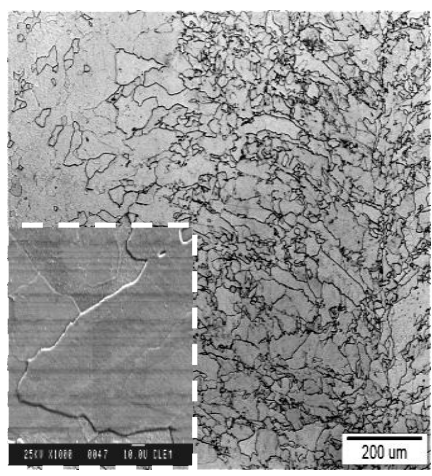

Fig. 2. Microstructure of WJ.

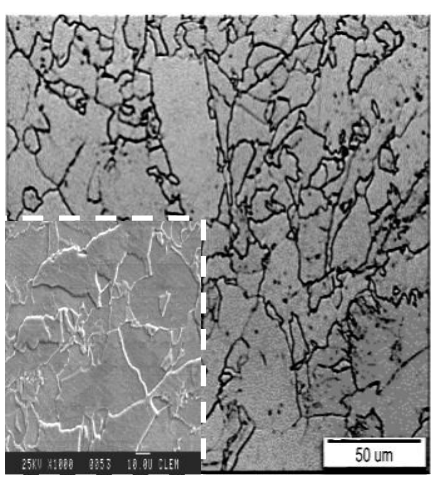

Fig. 3. Microstructure WM.

\subsection{Microhardness}

Table 3 shows the measured microhardness values of HV 0.1. Fig. 4 shows microhardness measurements throughout the weld. Table 3 shows the average of the 3 lines of measurement. Fig. 5 is an illustration of a single injection HV0.1. A graphical representation of the measured values is shown in Fig. 6. In the heat-affected region, there was a local decrease in microhardness values, which also corresponds to microstructural 
analysis of the base material. A coarse-grained ferritic structure was formed in the weld joint area.

Table 3. Microhardness of individual areas of welded steels DC06EK.

\begin{tabular}{|c|c|c|c|c|c|}
\hline $\begin{array}{c}\text { Measuring } \\
\text { area }\end{array}$ & BM1 & HAZ -M1 & WM & HAZ-M2 & BM2 \\
\hline HV 0.1 & $100-110$ & $105-210$ & $200-310$ & $107-210$ & $100-110$ \\
\hline
\end{tabular}
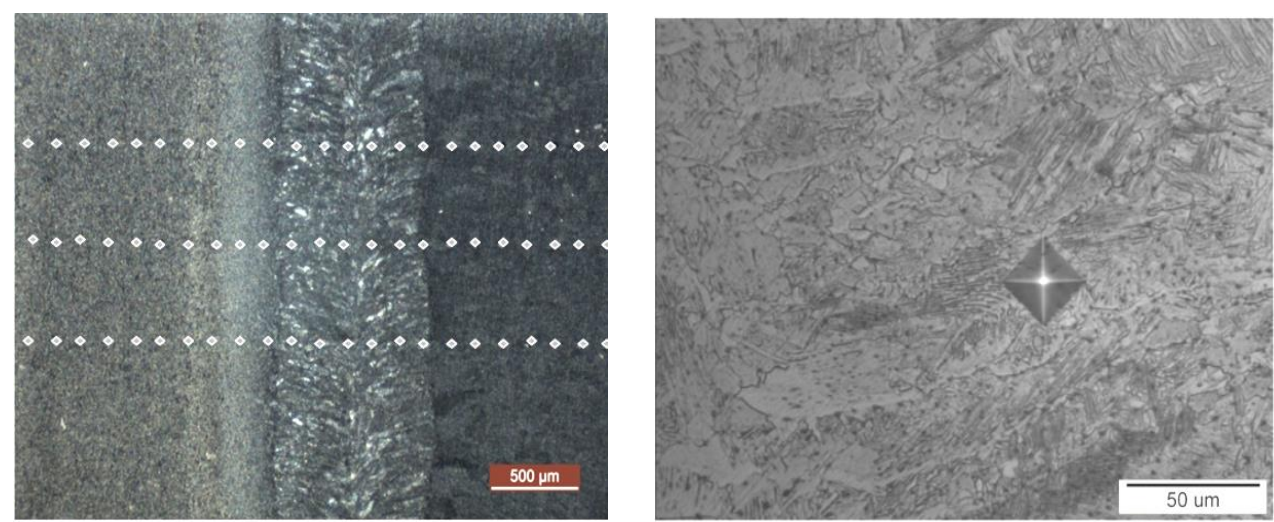

Fig. 4. Microhardness measurement throughout the weld.

Fig. 5. One sample injection HV0.1.

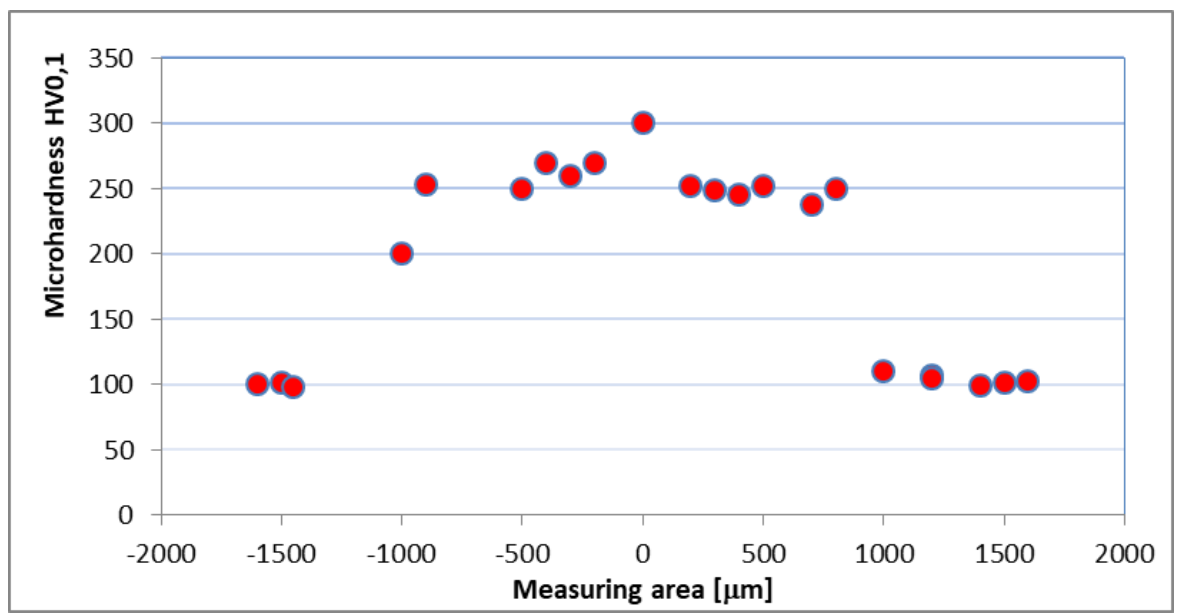

Fig. 6. Microhardness profile of DC06EK steel welded joint.

\subsection{Fatigue}

The fatigue life curve Fig. 7 was constructed to determine the degradation properties of the laser welded DC06EK steels. Dependence graphically shows $\sigma_{a}$ (voltage amplitude) on $N_{f}$ (number of cycles to break). 


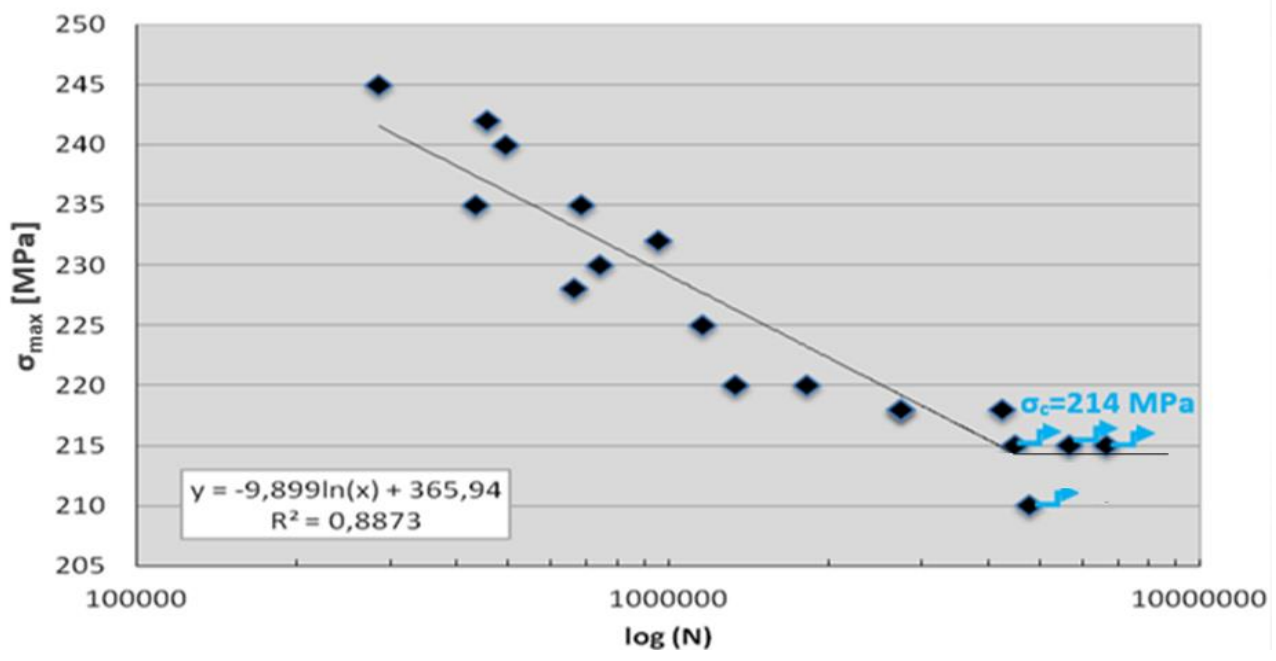

Fig.7. Wöhler curve - fatigue life of DC06EK steel welded joint.

Fig. 8 shows the morphology of the fracture surface. It is possible to see the progress lines and the area of the breakdown. On both sides of the base material of the steel DC06EK, a decohesive fracture was formed exclusively at the grain boundaries. Fig. 9, the straight grain boundaries and the glossy surface of the fracture surface are visible. These fractures originate at grain boundaries that are weakened by the presence of low-melting metal $(\mathrm{FeS}, \mathrm{MnS})$ or when the molten material is separated at the boundaries before they solidify $[13,14]$.

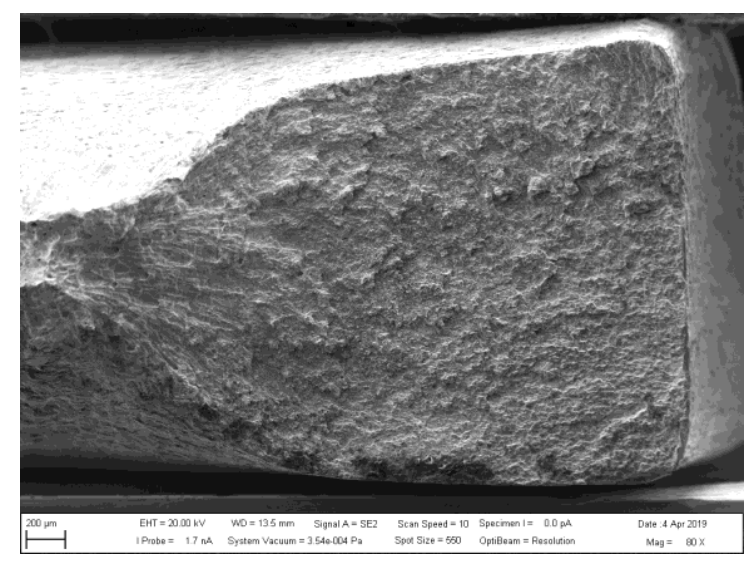

Fig. 8. Morphology of the fracture surface.

Fig. 9 The fracture surface of the DC06EK steel has not significant relief. In the base material decohesive fracture was formed exclusively over grain boundaries. Fracture surfaces BM are characterized predominantly by transcrystalline cleavage facets. Fig. 10, the straight grain boundaries and the glossy surface of the fracture surface WM are visible. According to $[15,16]$, cyclic deformation can lead to slippage asymmetry that leads to 
changes in the shape of the metal lattice crystals. The stress concentrations can then form along the grain boundaries, favoring the nucleation of the intercrystalline cracks.

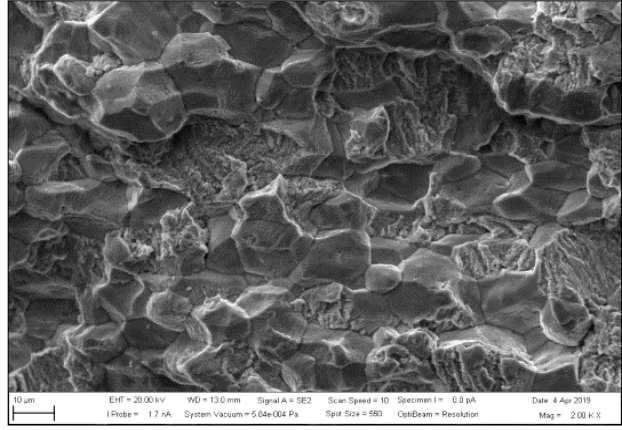

Fig. 9. Fracture surface DC06EK steels.

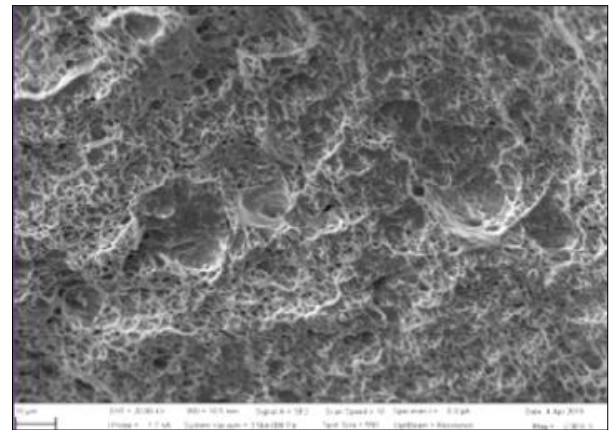

Fig. 10. Fracture surface WM.

\section{Conclusions}

In this paper, the effect of fatigue on the resulting properties of laser welded steel plates was evaluated. A low carbon steel combination of DC06EK was used as the experimental material.

- The microstructure of the DC06EK base material was made of polyhedric ferrite. A coarse-grained ferritic structure was formed in the TOO, resulting in a local drop in HV0.1 micro-hardness values.

- The structure of ZK was formed by polyhedric ferrite and bainite, which corresponds to the measured microhardness values in this area.

- The fatigue limit value $\sigma \mathrm{c}$ was $214 \mathrm{MPa}$. On both sides of the base material of the steel DC06EK, a decohesive fracture was formed exclusively at the grain boundaries.

- These fractures arise at grain boundaries that are weakened by the presence of lowmelting $\mathrm{FeS}, \mathrm{MnS}$, or when separating molten material at the boundaries before they solidify.

\section{References}

1. Z. Barsoum, T. Stenberg, E. Lindgren, Proc. Engin., 213, p.470-476, (2018)

2. A. Momeni et al, Metalurgija - J. of Metal, p.132-138, (2007)

3. D. Jankura, V. Varga, A. Metal. Slovaca, 1, p.25-33, (2000)

4. E. Kormaníková, K. Kotrasová, MATEC Web of Conf., 107, p.1-5, (2017)

5. J. Schijve, Int. Jour. of Fatigue, 25, 8, p.679-702, (2003)

6. J . Petrík and al., Ac. Metal Slov., 22, 3, p.195-205, (2016)

7. E. Kormaníková, K. Kotrasová, Jour. of Comp. Meth in Scien and Eng. 17, 4 (2017)

8. STN 420462: Stanovenie vel'kosti zrna ocelí a neželezných kovov.

9. P. Zimovčák, O. Milkovič, P. Zubko, M. Vojtko, Chem. Listy, 105 (2011)

10. ISO 6507-1:2018 Metallic materials -- Vickers hardness test -- Part 1: Test method.

11. ČSN 42 0363:1986 Zkoušení kovů. Zkoušky únavy kovů. Metodika zkoušení.

12. J. Petrík, Arch. of Metal. and Mat., 61, 4, p.1819-1824, (2016)

13. E. Bayraktar,+ et. al., J. of Mat.Proc.Tech., 189, 1-3, p.114-125, (2007) 
14. J. Petrík, Mat. Sc. - Medžiagotyra, 20, 1, p.21-24, (2014)

15. K. S. Panda, et. al, J. of Mat.Pro.Tech, 183, 2-3, p.321-332, (2007)

16. M. J. James, Eng. Frac. Mech, 77, p.29-41, (2010) 